\title{
The impact of reduced tillage and distance to field margin on predator functional diversity
}

\author{
Stine K. Jacobsen ${ }^{1}\left(\mathbb{D} \cdot\right.$ Lene Sigsgaard $^{1} \cdot$ Anna B. Johansen ${ }^{1} \cdot$ Kristian Thorup-Kristensen $^{1} \cdot$ Per M. Jensen $^{1}$
}

Received: 18 February 2021 / Accepted: 5 January 2022 / Published online: 11 January 2022

(c) The Author(s) 2022

\begin{abstract}
Introduction Agricultural intensification results in biodiversity loss through land conversion and management practices which negatively impact arthropods. The abundance and diversity of ground-dwelling predators, e.g. ground beetles (Coleoptera: Carabidae) and spiders (Araneae), are negatively affected by soil disturbances such as tillage. Reducing soil disturbances can potentially conserve arthropod populations in the field and reduce the use of chemical pest controls. The present study investigated the ground-dwelling predatory community using pitfall traps in cereal fields with three different levels of soil disturbance: conventional tillage, reduced tillage and no tillage under Conservation Agriculture management, in 2018 and 2019. Pitfall traps were placed in transects from the field margins. Overall, the activity-density of ground-dwelling predators was higher in fields with minimum soil disturbance and generally declined with increased distance to semi-natural habitats. Functional diversity, expressed by the body size of ground beetles, was also affected by soil disturbances; large ground beetles more consistently occurred in CA, while few or none of the largest ground beetles were found in RT and CT. A higher sample-heterogeneity in less disturbed fields was indicated by a more variable median and higher skewness in the number of predators in those fields. In 2019 only, species diversity was higher along field edges bordering semi-natural habitats when compared to the cropped area. Our results show that reduced tillage supports predator arthropod communities at a local scale: It also bolsters agro-ecosystem resilience by promoting a higher activity-density and by increasing the heterogeneity and functional diversity of ground-dwelling predators.

Implications for insect conservation The results obtained in the present study show that soil disturbances significantly influence arthropod abundance and diversity. Conservation of epigeic natural enemies in the agricultural landscape is improved by reducing soil-disturbing events such as tillage.
\end{abstract}

Keywords Soil disturbances $\cdot$ Conservation Agriculture $\cdot$ Biodiversity $\cdot$ Activity-density $\cdot$ Carabidae $\cdot$ Araneae $\cdot$ Seminatural habitats

\section{Introduction}

Agriculture is currently the largest contributor to biodiversity loss, mainly through the conversion of undisturbed land into intensely managed farmland (Tscharntke et al. 2005; Dudley and Alexander 2017; Habel et al. 2019). Conventional agriculture typically includes soil tillage and plant protection via chemical applications-, measures that affect both floral and faunal biodiversity (Dudley and Alexander

Stine K. Jacobsen

stikra@plen.ku.dk

1 Department of Plant and Environmental Sciences, University of Copenhagen, Thorvaldsensvej 40, 1871 Frederiksberg, Denmark
2017; Carmona et al. 2020). When soil is disturbed or tilled, ground living arthropods risk physical harm (Bell et al. 2001; Thorbek and Bilde 2004; Gurr et al. 2017) and can suffer from a depletion of food resources (Holland and Reynolds 2004; Navntoft et al. 2015). In such cases, biodiversity loss diminishes pest suppression, which in turn compounds reliance on chemical pest control (Snyder et al. 2006).

Decreasing soil-disturbances in crop management can increase the abundance and biodiversity of arthropods and plants (Navntoft et al. 2015; Tamburini et al. 2016; Chabert and Sarthou 2017; Rowen et al. 2020). Such positive effects can be achieved by establishing pesticide-free buffer zones (Navntoft et al. 2009), by reducing harrowing frequency (Navntoft et al. 2015) or by practicing Conservation Agriculture (Tamburini et al. 2016). Conservation 
Agriculture (CA) is an example of an agricultural management practice that utilizes the principles of minimum soil disturbance by direct sowing, permanent plant cover, e.g. crop or crop residues, and crop rotation (Farooq and Siddique 2015). Managing fields according to these principles can potentially provide resilient cropping systems that require less input yet maintain crop yield.

Abundant and sufficiently diverse populations of beneficial organisms are essential in a resilient cropping system (Tscharntke et al. 2005; Snyder et al. 2006; Jonsson et al. 2017; Snyder 2019). It is well established that even though predators are able to suppress pest populations (Symondson et al. 2002; Hassel and May 1986) the overall effect on pest suppression can be variable (Straub et al. 2008). Pest-predator relationships cannot be elucidated by species abundance and diversity alone. Recent evidence suggests that the functional diversity of predators plays an equally important role in the pest-predator relationship (McGill et al. 2006; Rusch et al. 2016; Greenop et al. 2018; Snyder 2019). Body size and habitat preference are particularly good predictors of pest control levels (Rusch et al. 2015). When the diversity of arthropod predator traits such as body size, feeding preferences or habitat requirements is higher, niche overlap and thus competition among predators is reduced (Davies et al. 2007; Cadotte et al. 2011). In such cases, the predator community not only experiences less competition between functional groups, it also collectively feeds on a broader range of prey species; the result of these interactions is a more resilient ecosystem with better pest control suppression.

Ground-dwelling beetles (Carabidae: Coleoptera) and spiders (Araneae: Arachnida) are two of the most abundant and diverse groups of ground-dwelling arthropod predators in cereal fields (Holland and Reynolds 2004). These two polyphagous groups benefit from a diverse diet (Symondson et al. 2006). The high degree of variation in ground beetles' functional traits, such as body size and prey consumption, is an indication that they potentially use complementary resources (Rouabah et al. 2014). Spiders, which are especially abundant early in the growth season (Sigsgaard 2000), differ from ground beetles by their feeding habits, foliar presence, and smaller body size (Nyffeler and Benz 1988; Öberg and Ekbom 2006). The resources that predatory ground beetles and spiders depend on, are more abundant and consistently present in less disturbed fields. Here, plant material on the soil surface provides a diverse microhabitat which in turn supports ground living detriticolous prey species as well as detritus feeders, such as the Collembola-an important alternative group of prey in the generalist predator diet (Bilde et al. 2000; Sigsgaard et al. 2001; Agustí et al. 2003). Soil disturbances via tillage reduce the abundance and the diversity of ground beetles and spiders when compared to fields with minimum tillage (Nawaz and Ahmad
2015; Tamburini et al. 2016); the process leading up to this encompasses a wide array of mechanisms.

Semi-natural habitats such as hedgerows and small, uncultivated areas established along bordering fields can create corridors for dispersal and provide refuge and resources for natural enemies during periods of unavailability in the field (Landis et al. 2005). These refugia are free from management practices and, because they remain largely undisturbed, provide ecological stability and agrobiodiversity at the local scale (Benton et al. 2003). To reap the benefits of semi-natural habitats in a cultivated area, natural enemies need to disperse into the field (Thomas and Marshall 1999; Tscharntke et al. 2016; Jacobsen et al. 2019). Semi-natural habitats can counter the effects of soil disturbances on predator dispersal in intensely managed fields. (Tamburini et al. 2016).

In the present study, we investigated the effect of three levels of soil disturbances (conventional tillage, reduced tillage and CA with no tillage), on the activity-density and diversity of ground-dwelling arthropod predators in cereal fields during the growing season of 2018 and 2019. More specifically, the study investigated whether (i) increased soil disturbance reduces the activity-density of ground beetles and spiders, (ii) species diversity and functional diversity of ground beetles are reduced with increasing soil disturbances, and (iii) the activity-density and diversity of grounddwelling arthropods are reduced with increasing distance to a semi-natural habitat.

\section{Materials and methods}

\section{Field sites}

The two-year field trial was performed in commercial cereal fields of winter wheat and spring barley near Sorø, Denmark $\left(55.26^{\circ} \mathrm{N} ; 11.33^{\circ} \mathrm{E}\right)$, on three neighboring farms practicing Conservation Agriculture (CA), reduced tillage (RT) and conventional tillage (CT). All crops were managed conventionally; chemical inputs were applied according to standard practice of plant protection (See Online Resource 1; Application of chemical pest control products and frequency). Both years, twelve fields, four of each cropping practice, all within a radius of approximately $10 \mathrm{~km}$, were used for the arthropod sampling. The fields were sown with winter wheat (predominantly) ( $n=9$ fields) or spring barley ( $n=3$ fields), and all fields had a semi-natural habitat in connection to the field (a small uncultivated set aside area or a hedgerow). Fields and semi-natural habitats were selected based on vegetation type, vegetation height, width of hedgerow/size of small set aside area, and geographical orientation (N/S/E/W) (Online Resource 2; Descriptions of semi-natural habitats). The sampling areas were placed so that the four orientations 
(N/S/E/W) were represented once for each cropping practice. Seven fields had winter wheat or spring barley both years, while five fields were replaced in 2019 due to rotations with other crops. Crop type and row distance in the crop was also recorded (Online Resource 2).

\section{Sampling of carabid beetles and spiders}

Sampling of ground-dwelling arthropods was conducted in June and July of 2018 and 2019. Arthropods were sampled by pitfall traps at distances of 0 (field edge), $6 \mathrm{~cm}$ and $12 \mathrm{~m}$ from a semi-natural habitat. Due to a seemingly different dynamic in the activity-density of ground beetles with increasing distance into the field between cropping practices in 2018, an additional distance of $24 \mathrm{~m}$ was added in 2019. One trap was placed per distance per field, providing a total of 72 traps in 2018 and 96 traps in 2019. The trap, a plastic cup ( $82 \mathrm{~mm}$ diameter, $70 \mathrm{~mm}$ deep) was buried in the soil with its rim level with the soil surface. After placement in the soil, each trap was partly filled with $200 \mathrm{ml}$ of liquid (mix of 1/3 ethylene glycol for arthropod preservation, $2 / 3$ water, and one drop of detergent) (Öberg and Ekbom 2006). A plastic lid $15 \mathrm{~cm}$ in diameter, supported by three large nails fixed $5-10 \mathrm{~cm}$ above the trap served as rain cover. After four days (96 h), pitfall traps were collected and arthropods were transferred to glass vials containing $70 \%$ ethanol (Navntoft et al. 2009). The two main groups of predators: ground beetles and spiders, were counted and morphologically identified to species (Carabidae) or family (Araneae) using taxonomic keys (Danmarks Fauna 1907-2004 2018; Roberts 1985). In addition, the body length of carabids was measured from mouthpart to end of abdomen, in order to assess functional diversity by trait.

\section{Faunal composition in the semi-natural habitats}

Habitat characteristics of the semi-natural habitats bordering the trial fields were recorded for each of the twelve locations in 2018, and for each of the five new locations in 2019 For each habitat, descriptions included the five most visually abundant woody and herbaceous plants and their approximate ground cover of the area. In addition, vegetation height (woody and herbaceous), hedgerow width, and bordering crop species were recorded (Online Resource 2).

\section{Data analysis}

Analyses were performed using the statistical software R, version 4.0.2 (R Core Team 2020). Data consisted of: (i) trap counts (no. of individuals) of ground beetles (Carabidae) and spiders (Araneae), as a measure of activity-density, (ii) size of ground beetles (no. of individuals within each size group), and (iii) species identified from pitfall traps, to investigate the diversity of ground beetles (Carabidae). The latter two with focus on ground beetles, due to their species richness, dispersal ability and specificity to habitat type, making them suitable indicator species of biodiversity. A comparison between the two types of semi-natural field margins (hedgerow and small set aside area) showed no statistical difference in the number of individuals $(p>0.05)$; therefore, data from these are merged in the following analyses. Models were validated by residual plots and qq-plots. Each year (2018 and 2019) was analyzed separately, with 2019 including the distance of $24 \mathrm{~m}$. In 2019, incidences resulted in five damaged traps; these were treated as missing data in the analyses.

Generalized linear mixed models (GLMM), with a Poisson distribution, in the $\mathrm{R}$ package $l m e 4$, function glmer, were used to analyze the activity-density and size of ground beetles and spiders (for sampling effort, see Online Resource 3). The model of activity-density had number of individuals (ground beetles and spiders) as the response variable, and as fixed effects it had time of season (June/July), cropping practice (CA, RT, CT) and distance to semi-natural habitat $(0 \mathrm{~m}$, $6 \mathrm{~m}, 12 \mathrm{~m}, 24 \mathrm{~m}$ ). Location (12 sites, four per cropping practice) was included as a random effect. Sizes of ground beetles were similarly modelled by a GLMM, and analyzed with number of individuals (ground beetles) as response variable and fixed effects: cropping practice (CA, RT, CT), distance to semi-natural habitat $(0 \mathrm{~m}, 6 \mathrm{~m}, 12 \mathrm{~m})$, and size (small/ medium/large/mega). The ground beetles were divided into groups according to their body size (length), based on the study by Rouabah et al. (2014), small: 3-9 mm, medium: 9.1-13 mm, large: $13.1-21 \mathrm{~mm}$, and mega: $21.1-40 \mathrm{~mm}$ (Table 1).

The distribution of data from pitfall traps was assessed by calculating the mean, the median, and the skewness (SKEW) in the number of individuals from each sample. SKEW represents the extent of which the distribution of data varies from a normal distribution and considers the extreme values in the dataset by expressing the likelihood of an event falling in the tail of the probability distribution. The calculations of the mean, median and the SKEW were performed for each management practice (CA, RT, CT) by distance $(0 \mathrm{~m}$, $6 \mathrm{~m}$, and $12 \mathrm{~m}$ [not $24 \mathrm{~m}])$ by year $(2018,2019)$. From these comparisons, spatial heterogeneity can be described, which permits a discussion of the resilience of the systems, under the assumption that samples with none or few individuals reflect a diminished ability to sustain predator populations (Cabell and Oelofse 2012).

Diversity was analyzed in the $\mathrm{R}$ package vegan, function diversity, by a Shannon-Wiener index ( $\left.\mathrm{H}^{\prime}\right)$, with the variables time (June, July), cropping practice (CA, RT, CT) and distance $(0 \mathrm{~m}, 6 \mathrm{~m}, 12 \mathrm{~m}$, and with $24 \mathrm{~m}$ included in 2019). Differences in H' depending on time, practice and distance were fitted to a linear model, function $\mathrm{lm}$. 
Table 1 Species of ground beetles (Coleoptera: Carabidae) identified from pitfall traps, their designated size group (small: 3-9 mm, medium: 9.1$13 \mathrm{~mm}$, large: $13.1-21 \mathrm{~mm}$, and mega: $21.1-40 \mathrm{~mm}$ ), average number of individuals per trap for each cropping practice (Conservation Agriculture (CA), Reduced Tillage (RT), Conventional Tillage (CT)), and total sum and percentage for each cropping practice. $\pm \mathrm{SE}$

\begin{tabular}{|c|c|c|c|c|c|c|c|}
\hline \multirow[t]{2}{*}{ Species } & \multirow[t]{2}{*}{ Size group } & \multicolumn{6}{|c|}{ Average number of individuals per pitfall trap } \\
\hline & & $\mathrm{CA}$ & Sum & RT & Sum & $\mathrm{CT}$ & Sum \\
\hline Carabus coriaceus & Mega & 0.01 & & 0 & & 0 & \\
\hline Carabus nemoralis & Mega & 0.3 & 0.32 & 0.12 & 0.12 & 0.01 & 0.01 \\
\hline Carabus violaceus & Mega & 0.01 & $13 \%$ & 0 & $4 \%$ & 0 & $0 \%$ \\
\hline Carabus granulatus & Large & 0 & & 0.01 & & 0.01 & \\
\hline Pterostichus melanarius & Large & 0.52 & 0.61 & 1.18 & 1.42 & 0.79 & 1.18 \\
\hline Pterostichus niger & Large & 0.09 & $25 \%$ & 0.23 & $43 \%$ & 0.38 & $43 \%$ \\
\hline Anisodactylus binotatus & Medium & 0.03 & & 0 & & 0.02 & \\
\hline Calathus fuscipes & Medium & 0.11 & & 0.19 & & 0 & \\
\hline Harpalus affinis & Medium & 0.1 & & 0.09 & & 0.23 & \\
\hline Harpalus latus & Medium & 0.01 & & 0.01 & & 0 & \\
\hline Harpalus melancholicus & Medium & 0.01 & 0.74 & 0 & 0.6 & 0 & 0.94 \\
\hline Harpalus rubripes & Medium & 0.03 & $31 \%$ & 0.01 & $18 \%$ & 0 & $34 \%$ \\
\hline Harpalus rufipes & Medium & 0.16 & & 0.15 & & 0.47 & \\
\hline Nebria brevicollis & Medium & 0.17 & & 0.12 & & 0.06 & \\
\hline Poecilus cupreus & Medium & 0.06 & & 0.01 & & 0.02 & \\
\hline Poecilus versicolor & Medium & 0.06 & & 0.02 & & 0.14 & \\
\hline Agonum muelleri & Small & 0.03 & & 0.07 & & 0.01 & \\
\hline Anchomenus dorsalis & Small & 0.06 & & 0.36 & & 0.13 & \\
\hline Asaphidion curtum & Small & 0 & & 0.01 & & 0.01 & \\
\hline Badister lacertosus & Small & 0.01 & & 0 & & 0.01 & \\
\hline Bembidion articulatum & Small & 0.01 & & 0.03 & & 0.01 & \\
\hline Bembidion lampros & Small & 0.52 & & 0.4 & & 0.29 & \\
\hline Bembidion obtusum & Small & 0 & & 0.02 & & 0.01 & \\
\hline Bembidion qaudrimaculatum & Small & 0 & & 0 & & 0.02 & \\
\hline Calathus melanocéphalus & Small & 0 & & 0.01 & & 0 & \\
\hline Clivina fossor & Small & 0 & 0.74 & 0.01 & 1.14 & 0.04 & 0.63 \\
\hline Harpalus melleti & Small & 0 & $31 \%$ & 0.01 & $35 \%$ & 0.01 & $23 \%$ \\
\hline Leistus ferrugineus & Small & 0 & & 0 & & 0.01 & \\
\hline Loricera pilicornis & Small & 0.01 & & 0.07 & & 0.02 & \\
\hline Notiophilus aesthuans & Small & 0.02 & & 0.04 & & 0 & \\
\hline Notiophilus biguttatus & Small & 0.02 & & 0 & & 0.01 & \\
\hline Notiophilus palustris & Small & 0.03 & & 0.01 & & 0.01 & \\
\hline Notiophilus rufipes & Small & 0.02 & & 0.01 & & 0.01 & \\
\hline Pterostichus strenииs & Small & 0 & & 0 & & 0.01 & \\
\hline Stomis pumicatus & Small & 0 & & 0.01 & & 0 & \\
\hline Synuchus vivalis & Small & 0.01 & & 0.03 & & 0.01 & \\
\hline Trechus quadristriatus & Small & 0 & & 0.05 & & 0.01 & \\
\hline Sum & & 2.41 & & 3.28 & & 2.76 & \\
\hline
\end{tabular}

\section{Results}

\section{Activity-density of arthropod predators}

The high number of predators in CA compared to RT and CT (Fig. 1a) largely originated from samples collected at the field margins ( $0 \mathrm{~m}$, Fig. $1 \mathrm{~b})$, which in some samples contained an extremely high number of individuals. We found 37 species of ground beetles (Table 1) and the spiders could be assigned to one of two main families of spiders or as immatures: Linyphiidae, 55\%; Lycosidae, 9\%; immatures, $35 \%$. The remaining $1 \%$ of the spiders included Araneidae, Clubionidae, Gnaphosidae, Pisauridae, Tetragnathidae and Thomisidae.

There was a seasonal difference in the abundance of predators both years, with more predators in June (2018: 550; 2019: 1305 predators total) than in July (2018: 421; 2019: 1014 predators total $)(p<0.001, \mathrm{z}$-value $=4.14$, $\mathrm{df}=65$ ). In 2018, there was no overall effect of either cropping practice or of distance on the activity-density of 

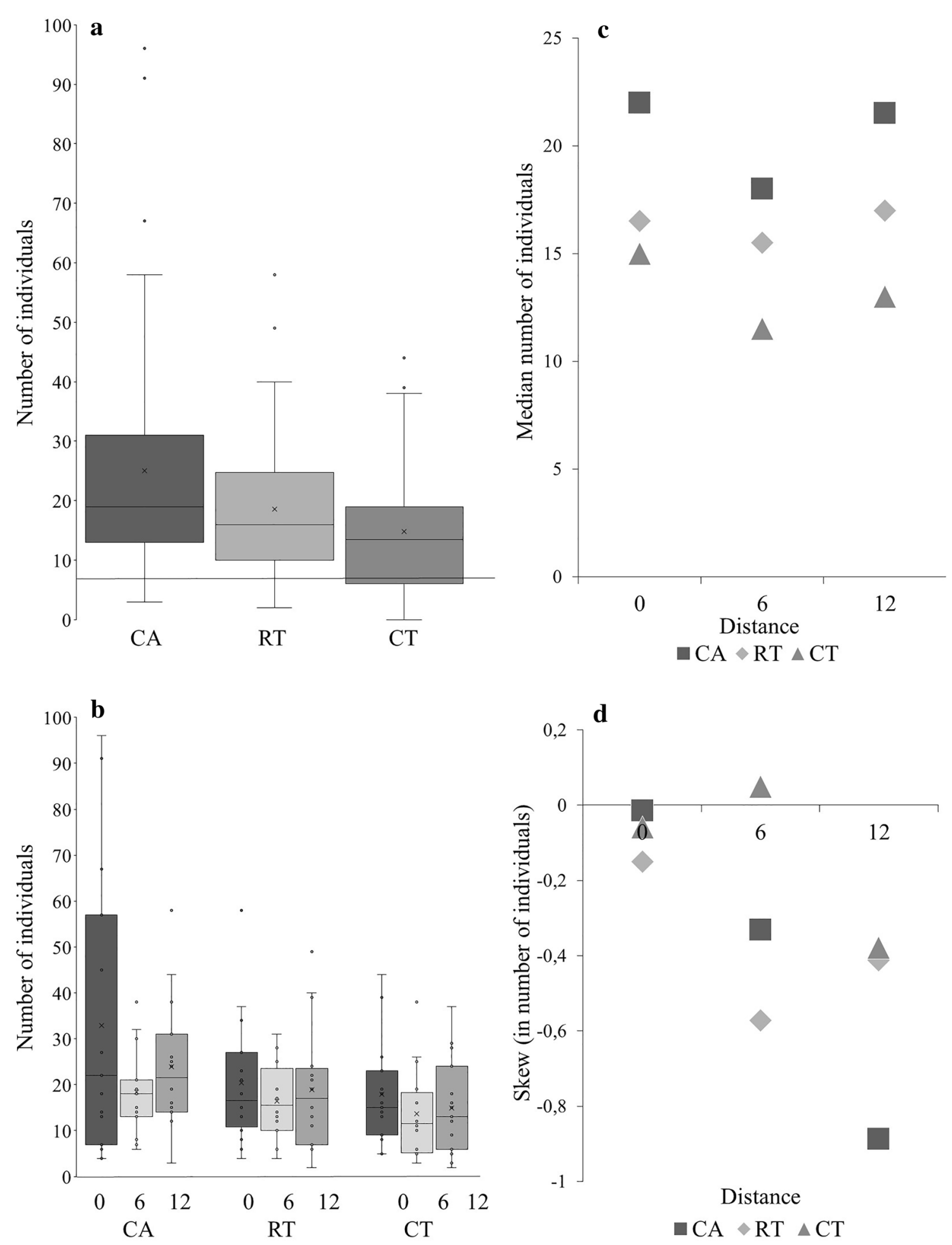

Fig. 1 Calculated mean, median and SKEW of the number of ground beetles and spiders in pitfall traps for each cropping practice $(C A$ Conservation agriculture, $R T$ Reduced tillage, $C T$ Conventional till-

age), at distances 0-12 m. a Mean number of individuals, b Mean number of individuals for each distance, $\mathbf{c}$ Median number of individuals, and $\mathbf{d}$ SKEW in the number of individuals, $\pm \mathrm{StDev}$

predators. The interaction of distance and cropping practice was significant (Fig. 2a); at $6 \mathrm{~m}$ into the field, CA (12.9 (9.0 predators/trap) $(p=0.004, \mathrm{z}$-value $=-2.88, \mathrm{df}=62)$, while there was no interaction between cropping practice and distance between CA and RT (11.0 predators/trap). At 
Fig. 2 Number of predators per pitfall trap in $\mathbf{a} 2018$ and $\mathbf{b}$ 2019; ground beetles (Carabidae) and spiders (Araneae) in three different cropping practices (CA Conservation agriculture, $R T$ Reduced tillage, $C T$ Conventional tillage), at four different distances $(0 \mathrm{~m}, 6 \mathrm{~m}$, $12 \mathrm{~m}$ and $24 \mathrm{~m}), \pm \mathrm{SE}$ of the total number of predators

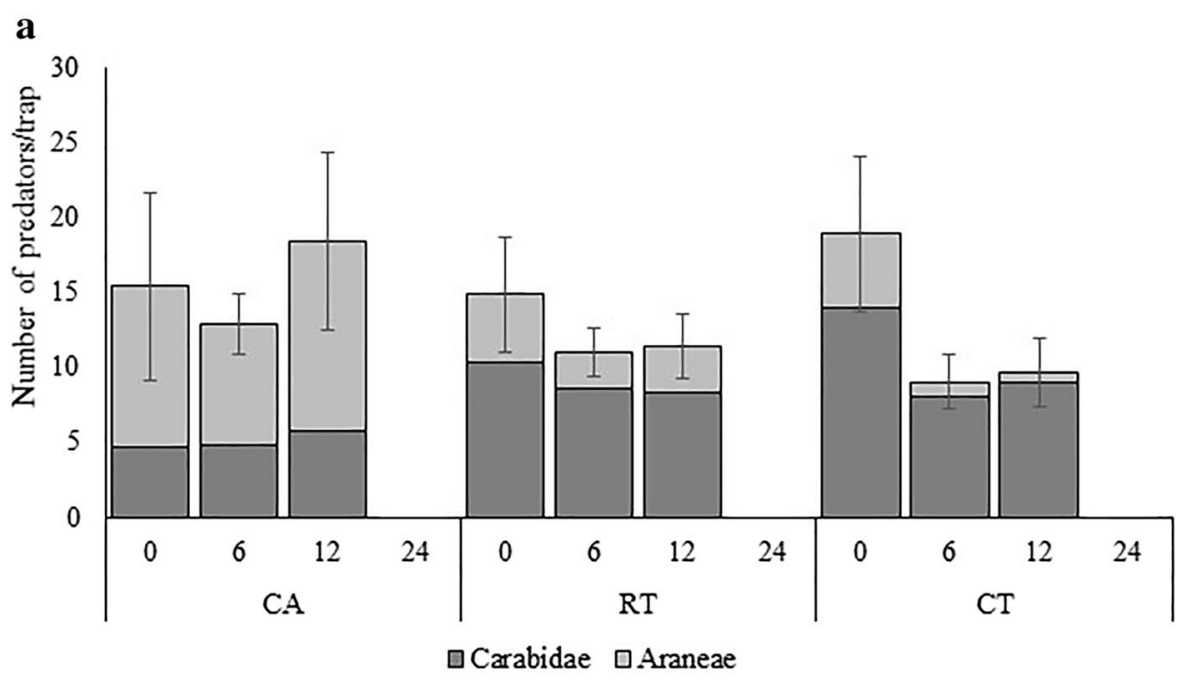

b

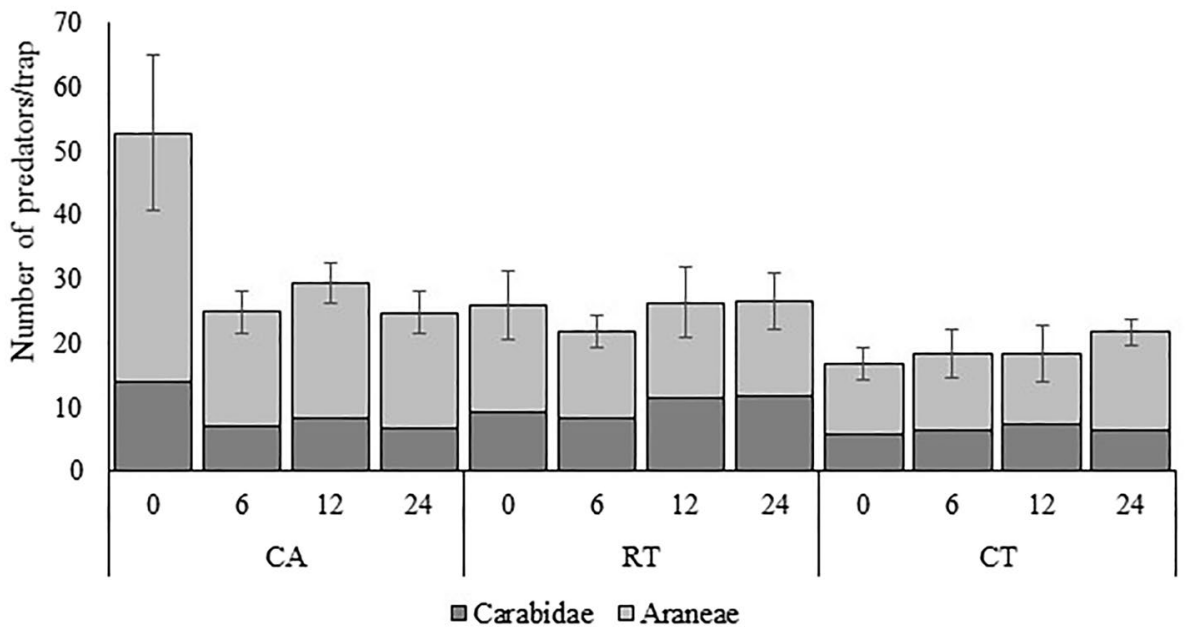

$12 \mathrm{~m}$ into the field, the activity-density of predators was also dependent on cropping practice, being higher in CA (18.4 predators/trap) compared to RT (11.4 predators/trap) $(p=0.02, \mathrm{z}$-value $=-2.41, \mathrm{df}=62)$ and CT (9.6 predators/ trap) $(p<0.001, \mathrm{z}$-value $=-4.60, \mathrm{df}=62)$.

In comparing 2019 distances to the same 2018 distances (0-12 m), the activity-density of predators was lower in CT (410 predators total) compared to CA (779 predators total) $(p=0.005, \mathrm{z}$-value $=-2.82, \mathrm{df}=61)$, while there was no significant difference in the activity-density between CA and RT (594 predators total) (Fig. 2b). The same year, an overall higher activity-density of predators at $0 \mathrm{~m}$ compared to $6 \mathrm{~m}$ and $12 \mathrm{~m}$ was found $(6 \mathrm{~m}: p<0.001, \mathrm{z}$-value $=-5.78$, $\mathrm{df}=61 ; 12 \mathrm{~m}: p<0.001, \mathrm{z}$-value $=-4.05, \mathrm{df}=61)$. In addition, the interaction effect of distance and cropping practice was highly significant. Activity-density differed between tillage practices at both $6 \mathrm{~m}$ and $12 \mathrm{~m}$, between CA and RT (both distances; $p<0.001 ; 6 \mathrm{~m}$ : $\mathrm{z}$-value $=4.07, \mathrm{df}=58$; $12 \mathrm{~m}$ : $\mathrm{z}$-value $=4.92, \mathrm{df}=58$ ) and between CA and CT (both distances; $p<0.001, \mathrm{df}=58 ; 6 \mathrm{~m}: \mathrm{z}$-value $=5.32 ; 12 \mathrm{~m}$ : $\mathrm{z}$-value $=5.76$ ). Activity-density in 2019, including the distance of $24 \mathrm{~m}$, was also significantly lower at $6 \mathrm{~m}, 12 \mathrm{~m}$ and $24 \mathrm{~m}$ compared to $0 \mathrm{~m}(p<0.001, \mathrm{df}=83$ at all distances; $6 \mathrm{~m}: \mathrm{z}$-value $=-5.93 ; 12 \mathrm{~m}: \mathrm{z}$-value $=-4.04 ; 24 \mathrm{~m}$ : $\mathrm{z}$-value $=-5.87)$. The activity-density differed significantly between CA and CT at $24 \mathrm{~m}$, with CA (24.8 predators/ trap) being higher than CT (19.0 predators/trap) $(p<0.012$, $\mathrm{z}$-value $=-2.52, \mathrm{df}=83)$, but not different from RT $(26.6$ predators/trap).

\section{Size distribution of carabids}

The difference in size distribution was clearly caused by mega-sized beetles, which were almost exclusively found in CA. A low number of mega-sized beetles in CT and RT was associated with a higher number of large beetles, while the total number of large and mega-sized beetles were comparable across all cropping practices (Table 1). 
In 2018, large ground beetles were more numerous than any other size category $(p<0.001, \mathrm{df}=63$ in all instances; small: $\mathrm{z}$-value $=-9.30$; medium: $\mathrm{z}$-value $=-4.89$; mega: $\mathrm{z}$-value $=-11.72$ ) (Fig. 3). Also, there was a highly significant interaction between cropping practice and size of ground beetles with CA beetle sizes being more equally distributed over distances in comparison to RT (small: $p=0.05, \mathrm{Z}$-value $=-1.96, \mathrm{df}=59$; medium: $p<0.001$, $\mathrm{z}$-value $=-4.71, \mathrm{df}=59$; mega: $p<0.001, \mathrm{z}$-value $=-5.54$, $\mathrm{df}=59$ ), and CT (small: $p<0.001, \mathrm{z}$-value $=-4.05, \mathrm{df}=59$; medium: $p=0.01, \mathrm{z}$-value $=-2.47, \mathrm{df}=59$; mega: $p<0.001$, $\mathrm{z}$-value $=-4.44, \mathrm{df}=59)($ Fig. $3 \mathrm{a})$. There was no overall effect of distance to semi-natural habitat in the size differences of the ground beetles $(p>0.05)$.

In 2019, there was a significantly smaller proportion of mega-sized ground beetles, compared to the other three size groups $(p<0.001, \mathrm{z}$-value $=3.38, \mathrm{df}=59)$. As in 2018, a significant interaction was found between cropping practice and ground beetle size, i.e. in the distribution of the medium $(p<0.001, \mathrm{z}$-value $=-3.50, \mathrm{df}=59)$ and megasized $(p=0.008, \mathrm{z}$-value $=-2.64, \mathrm{df}=59)$ ground beetles in CA and RT (Fig. 3b). No interaction between cropping practice and body size were found between CA and CT.

\section{Resilience determined by variation}

Resilience in cropping systems is dependent on the ability of the ecological community to cope with disturbances and maintain stability, i.e. a resilient agroecosystem is able to recover from and adapt to various stressors, such as disturbances and extreme weather events. A higher mean in the number of individuals per trap was associated with a higher standard deviation in CA (Fig. 1a); this was also reflected in the standard deviation in number of individuals at different
Fig. 3 Size group distribution (small, medium, large, mega) of ground beetles. Proportion of ground beetles (Carabidae) within each size group per cropping practice (x-axis) in pitfall traps 0-12 m (CA Conservation agriculture, $R T$ Reduced tillage, $C T$ Conventional tillage), in a 2018 , and b 2019, \pm SE
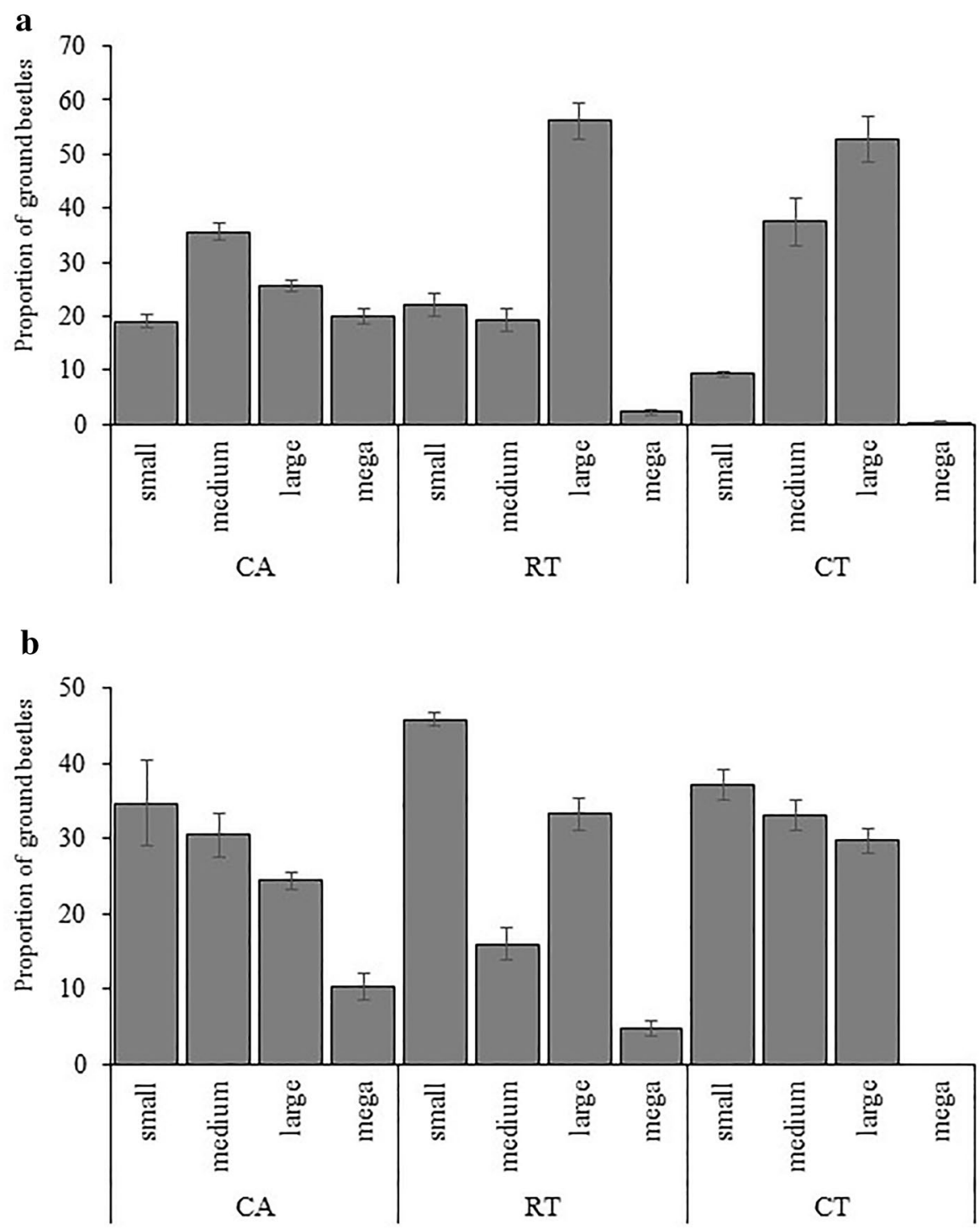
distances (Fig. 1b), i.e. the variation in the mean number is created by extreme values in the data, due to spatial heterogeneity. Therefore, examining the median and skewness of the data is a better way of elucidating resilience. The median shows a continuous decrease; $\mathrm{CA}>\mathrm{RT}>\mathrm{CT}$, where $\mathrm{CA}$ has a higher median of trap catches across all fields and at all distances into the field (Fig. 1c). Similarly, the generally more negative skew indicates that there is an underrepresentation of low numbers in CA compared to RT and CT, but this primarily occurs at $12 \mathrm{~m}$ from the edge of the field (Fig. 1d). The higher skewness of data, combined with the higher median number of ground beetles and spiders in pitfall traps, suggests that the distribution of natural enemies is more heterogeneous in fields with reduced soil disturbances. Despite the higher heterogeneity, traps placed in the fields with minimal soil disturbances rarely included a low number of predators.

\section{Carabid species diversity}

A total of 37 species of the family Carabidae (Coleoptera) were identified from the pitfall traps (Table 1). The Shannon-Wiener diversity index (H') ranged from 0.92 to 2.24 (Table 2). In 2018, no differences of the Shannon-Wiener diversity H' were found, neither between the two annual sampling times $(p=0.67)$, nor the cropping practices (CA vs RT: $p=0.11, \mathrm{CT}: p=0.15)$ or distances ( $0 \mathrm{~m}$ vs $6 \mathrm{~m}$ : $p=0.32,12 \mathrm{~m}: p=0.30)$. In 2019, a higher overall diversity was found at $0 \mathrm{~m}$ compared to $6 \mathrm{~m}(p=0.01$, $\mathrm{t}$-value $=-3.17$, $\mathrm{df}=12), 12 \mathrm{~m}(p=0.002, \mathrm{t}$-value $=-4.26, \mathrm{df}=12)$, and $24 \mathrm{~m}$ $(p=0.004, \mathrm{t}$-value $=-3.31, \mathrm{df}=17)$. Cropping practice affected H', which was lower in CA than in RT ( $p=0.005$, $\mathrm{t}$-value $=3.47, \mathrm{df}=12)$ and in CT $(p=0.02, \mathrm{t}$-value $=2.78$, $\mathrm{df}=12)$. No interaction effects were found in $2019(p>0.7$ in all instances).

\section{Discussion}

With this study, we show that reducing soil disturbances in agroecosystems improves the survival and functional diversity of ground beetles and spiders. At a local scale, seminatural habitats can be a source of natural enemies in the cropped area; an effect best exploited in less disturbed fields.

In the first year of sampling, ground beetles were less affected by cropping practices than were spiders. This is in line with the results of Rowen et al. (2020), who found that the degree of tilling does not affect ground beetle abundance, and of Thorbek and Bilde (2004), who found that spiders were more sensitive to soil treatments than beetles. Cole et al. (2005) reached similar conclusions and suggested that spiders could be a reliable indicator for the influence of farming practices on invertebrates. Both of these arthropod groups are common in the agroecosystem, and it is likely that an investigation of other groups, which are less common and with other life cycles, could reveal further consequences of soil tillage (Sapkota et al. 2012). Soil with plant material on its surface holds more food and creates a more structurally diverse environment, which leads to improved habitat and temperature stability - all of which is favorable for spiders (Tamburini et al. 2016). The relatively few number of ground beetles in CA is likely an expression of competition for resources with other predatory assemblages, here evident from the high number of spiders in CA in 2018 (Fig. 2a; Online Resource 4). This contributes to shaping community composition and overall pest suppression (Rusch et al.
Table 2 Estimated values of the Shannon-Wiener diversity index $\left(\mathrm{H}^{\prime}\right)$ for June and July, 2018 and 2019, based on cropping practice (Conservation Agriculture (CA), Reduced Tillage (RT), Conventional Tillage (CT)) and distance to semi-natural habitat $(0 \mathrm{~m}, 6 \mathrm{~m}$, $12 \mathrm{~m}$ both years, $24 \mathrm{~m}$ included in 2019). Mean values for time and each distance are included for $0-12 \mathrm{~m}$

\begin{tabular}{|c|c|c|c|c|c|c|}
\hline \multirow[t]{2}{*}{ Cropping practice } & \multirow[t]{2}{*}{ Distance (m) } & \multicolumn{2}{|l|}{2018} & \multicolumn{2}{|l|}{2019} & \multirow[t]{2}{*}{ Mean } \\
\hline & & June & July & June & July & \\
\hline \multirow[t]{4}{*}{ CA } & 0 & 1.89 & 1.66 & 1.94 & 1.81 & 1.83 \\
\hline & 6 & 1.57 & 2.07 & 1.80 & 1.40 & 1.71 \\
\hline & 12 & 2.14 & 2.08 & 1.53 & 1.54 & 1.82 \\
\hline & 24 & - & - & 1.66 & 1.41 & \\
\hline Mean (0-12) & & 1.87 & 1.94 & 1.76 & 1.58 & \\
\hline \multirow[t]{4}{*}{ RT } & 0 & 1.90 & 2.24 & 2.07 & 2.09 & 2.08 \\
\hline & 6 & 1.05 & 1.92 & 1.94 & 1.81 & 1.68 \\
\hline & 12 & 1.14 & 0.92 & 1.72 & 1.90 & 1.42 \\
\hline & 24 & - & - & 1.98 & 2.11 & \\
\hline Mean $(0-12)$ & & 1.36 & 1.69 & 1.91 & 1.93 & \\
\hline \multirow[t]{4}{*}{ CT } & 0 & 1.81 & 1.47 & 1.87 & 2.21 & 1.84 \\
\hline & 6 & 1.62 & 1.40 & 1.87 & 1.81 & 1.68 \\
\hline & 12 & 1.55 & 1.59 & 1.80 & 1.67 & 1.65 \\
\hline & 24 & - & - & 1.60 & 1.57 & \\
\hline Mean $(0-12)$ & & 1.66 & 1.49 & 1.85 & 1.90 & \\
\hline
\end{tabular}


2016). Unusually high temperatures during the cropping season of 2018 likely induced a higher reproduction rate in and around fields, which became evident the following year. In 2019, there were more ground beetles and spiders in CA fields than in RT and CT fields. Both years, a strong correlation between cropping practice and activity-density was found-even at six meters into the field. This can be an indication that the beneficial effects of surrounding seminatural habitats are stronger if soil disturbances are reduced to a minimum in the field. It can also be a reflection that the arthropod community is less dependent on semi-natural habitats in minimally disturbed fields where more resources are available, an observation also made by Tamburini et al. (2016). Differing weather conditions between the two years was reflected by the abundance of Grey partridges (Perdix perdix) nesting in the fields of the three farms (Pedersen and Wejdling 2019). Partridge abundance was about twice as high on CA compared to RT. In addition to soil disturbances, the use of chemical plant protection products for pest control can also affect the abundance of arthropods in the field. Among the pest control products, those containing pyrethroids can be especially harmful to non-target organisms (Giglio et al. 2017). In both years, and before 2018, chemical products were applied one to two times per year in the majority of RT and CT fields, while none or one application was used in CA fields (Online Resource 1). This could have potentially contributed to the results obtained in the present study.

Arthropod community composition and its functional diversity are essential for creating resilient cropping systems. This study found that an important trait of ground beetles, namely body size, is strongly affected by the level of soil disturbances; mega-sized ground beetle species were especially sensitive to tillage. In addition, mega-sized ground beetles were not particularly associated with distance to semi-natural habitat, i.e. also at $0 \mathrm{~m}$ in CT fields there was no occurrence of mega-sized ground beetles. Mega-sized ground beetles $(21.1-40 \mathrm{~mm}$ ) feed on a bigger size and a higher number of prey than smaller beetles and play a significant role in supporting pest suppression in the field (Rouabah et al. 2014). The three mega-sized beetle species found in the present study, Carabus coriaceus, C. nemoralis and $C$. violaceus, are all common to undisturbed areas in Denmark and can be found in agroecosystems with favorable conditions. These species are essential for shaping the arthropod community assembly by expanding the niche composition in cropping systems (Rusch et al. 2015), e.g. by covering a broader feeding range, while also being vulnerable to disturbances (Nolte et al. 2019). In less disturbed fields, e.g. those that are not subjected to tillage and with more plant litter, essential beetle species will not only find food in the seminatural habitats bordering the fields, they will also find food in the cropped area. In the present study, the composition of the four body size categories was more even in CA. This was indicated by the differences in interaction effects in fields of minimum soil disturbances when compared to reduced and conventional tillage regimes, showing a higher functional diversity in CA. When the size distribution of predators is more even, niche range is expanded and the natural regulation of pests is enhanced by the suppression of a wider range of prey. Previous studies investigating the use of functional traits to predict ecosystem services have also found a correlation between body size and pest suppression (Rouabah et al. 2014; Rusch et al. 2015).

High heterogeneity, typically associated with undisturbed areas such as semi-natural habitats, favors higher arthropod abundance and species richness (Attwood et al. 2008) which potentially creates more stable predator-prey interactions (Rusch et al. 2016). These conditions are essential for resilience, which is driven both by functional diversity and the presence of redundant species at various scales (Peterson et al. 1998). $\mathrm{Ng}$ et al. (2017) suggest that maintaining a cropped area with minimum soil tillage, among other things, can provide favorable habitat and resources for the carabid community. At a local scale, habitat heterogeneity is associated with higher biodiversity (Benton et al. 2003), which lends support to the finding of this study, where heterogeneous conditions in the cropped area of minimum tillage is likely a contributing factor to the higher observed functional diversity.

The biodiversity of organisms on the soil surface is linked to soil disturbances, e.g. tillage interferes with the macrofauna and alters the structure and stability of the soil (Holland and Reynolds 2004). It is further expected that undisturbed semi-natural habitats containing a higher diversity of plants and arthropods, will in turn favor predator diversity (Benton et al. 2003). However, in the first year of field trials, no differences in carabid biodiversity were found, neither between the semi-natural habitat and field, nor between cropping practices. Other studies have also not found a correlation between reduced tillage and carabid biodiversity (Lalonde et al. 2011; Boscutti et al. 2015). In the second year, the overall diversity of ground beetles in the seminatural habitat was higher compared to the field, and slightly lower in CA than in RT and CT. These results suggest that species diversity is multi-faceted and likely the result of a combination of factors, e.g. level of soil disturbances, abundance of organisms, weather conditions, etc.

Consistent differences in captures, as reflected by the median number of predators per trap (as opposed to means), and the larger SKEW of data in CA, appear to be important indicators for elucidating the differences between cropping practices. Data heterogeneity compromises the assumption of the normal distribution statistical models; therefore, the outcome of statistical analyses should be interpreted with caution. Further studies, specifically addressing the spatial 
heterogeneity observed here, may allow for a better understanding of the variation in biological functionality within semi-natural habitats under different cropping practices.

Our study adds to the existing literature, which propose that the impact on both abundance and functional diversity of predators vary according to the level of disturbance in agroecosystems (Cole et al. 2005; Boscutti et al. 2015). The results not only highlight the complexity of the system and variation at a local scale, they also demonstrate the importance of considering species functionality rather than a general contribution of species diversity (Boscutti et al. 2015; Greenop et al. 2018). Based on existing literature and present findings, agricultural management needs to carefully consider the level and frequency of disturbance levels in the agroecosystem to conserve organisms. Minimum soil disturbances better enable predatory arthropod populations to persist in the agricultural landscape and resilience in predator populations may hereby reduce the need for chemical input during the cropping season. Future studies need to address the spatial dynamics of the predatory communities in minimally disturbed cropping systems, and expand the exploration of trophic interactions with the plant community, in order to increase the conservation of organisms across orders.

Supplementary Information The online version contains supplementary material available at https://doi.org/10.1007/s10841-022-00370-x.

Acknowledgements The authors would like to thank the farmers in the project, Anja Amtoft for proof reading the manuscript, and Henrik Kruse Rasmussen and Andreas Skov Rasmussen from AGROVI, farmers' advisory service. The project was funded by the 15 June Foundation (Project Number 2016-A-129), with support from the project 'Grønne Marker \& Stærke Rødder', funded by The Velux Foundation (Project Number 13602).

Author contributions PM, LS and KTK conceived the research. SKJ, LS and PM contributed to design of the experiment. SKJ, LS PM and AJ conducted experiments. SKJ and PM conducted statistical analyses and data interpretation. SKJ wrote the manuscript. All authors contributed to revisions of the manuscript. All authors read and approved the final version of the manuscript.

Data availability Data will be made available in a digital data repository upon acceptance of the manuscript.

\section{Declarations}

Conflict of Interest The authors declare no conflicts of interest.

Open Access This article is licensed under a Creative Commons Attribution 4.0 International License, which permits use, sharing, adaptation, distribution and reproduction in any medium or format, as long as you give appropriate credit to the original author(s) and the source, provide a link to the Creative Commons licence, and indicate if changes were made. The images or other third party material in this article are included in the article's Creative Commons licence, unless indicated otherwise in a credit line to the material. If material is not included in the article's Creative Commons licence and your intended use is not permitted by statutory regulation or exceeds the permitted use, you will need to obtain permission directly from the copyright holder. To view a copy of this licence, visit http://creativecommons.org/licenses/by/4.0/.

\section{References}

Agustí N, Shayler SP, Harwood JD, Vaughan IP, Sunderland KD, Symondson WOC (2003) Collembola as alternative prey sustaining spiders in arable ecosystems: prey detection within predators using molecular markers. Mol Ecol 12:3467-3475

Attwood SJ, Maron M, House APN, Zammit C (2008) Do arthropod assemblages display globally consistent responses to intensified agricultural land use and management? Glob Ecol Biogeogr 17:585-599

Bell JR, Wheater CP, Cullen WR (2001) The implications of grassland and heathland management for the conservation of spider communities: a review. J Zool 255:377-387

Benton TG, Vickery JA, Wilson JD (2003) Farmland diversity: is habitat heterogeneity the key? Trends Ecol Evol 18:182-188

Bilde T, Axelsen JA, Toft S (2000) The value of Collembola from agricultural soils as food for a generalist predator. J Appl Ecol 37:672-683

Boscutti F, Sigura M, Gambon N, Lagazio C, Krüsi BO, Bonfanti P (2015) Conservation tillage affects species composition but not species diversity: a comparative study in Northern Italy. Environ Manage 55:443-452

Cabell JF, Oelofse M (2012) An indicator framework for assessing agroecosystem resilience. Ecol Soc 17:18

Cadotte MW, Carscadden K, Mirotchnick N (2011) Beyond species: functional diversity and the maintenance of ecological processes and services. J Appl Entomol 48:1079-1087

Carmona CP, Guerrero I, Peco B, Morales MB, Oñate JJ, Pärt T, Tscharntke T, Liira J, Aavik T, Emmerson M, Berendse F, Ceryngier P, Bretagnolle V, Weisser WW, Bengtsson J (2020) Agriculture intensification reduces plant taxonomic and functional diversity across European arable systems. Funct Ecol 34:1448-1460

Chabert A, Sarthou J-P (2017) Practices of conservation agriculture prevail over cropping systems and landscape heterogeneity in understanding the ecosystem service of aphid biocontrol. Agric Ecosyst Environ 249:70-79

Cole LJ, McCracken DI, Downie IS, Dennis P, Foster GN, Waterhouse T, Murphy KJ, Griffin AL, Kennedy MP (2005) Comparing the effects of farming practices on ground beetle (Coleoptera: Carabidae) and spider (Araneae) assemblages of Scottish farmland. Biodivers Conserv 14:441-460

Davies TJ, Meiri S, Barraclough TG, Gittleman JL (2007) Species coexistence and character divergence across carnivores. Ecol Lett 10:146-152

Dudley N, Alexander S (2017) Agriculture and biodiversity: a review. Biodiversity 18:45-49

Farooq M, Siddique KHM (2015) Conservation agriculture: concepts, brief history, and impacts on agricultural systems. In: Farooq M, Siddique KHM (eds.) Conservation agriculture. Springer International Publishing, Switzerland.

Danmarks Fauna 1907-2004 (2018) Dansk naturhistorisk forening, G.E.C. Gad forlag. Copenhagen, DK.

Giglio A, Cavaliere F, Giulianini PG, Mazzei A, Talarico F, Vommaro ML, Brandmayr P (2017) Impact of agrochemicals on non-target species: Calathus fuscipes Goeze 1777 (Coleoptera: carabidae) as model. Ecotoxicol Environ Saf 142:522-529 
Greenop A, Woodcock BA, Wilby A, Cook SM, Pywell RF (2018) Functional diversity positively affects prey suppression by invertebrate predators: a meta-analysis. Ecology 99:1771-1782

Gurr GM, Wratten SD, Landis DA, You M (2017) Habitat management to suppress pest populations: progress and prospects. Annu Rev Entomol 62:91-109

Habel JC, Ulrich W, Biburger N, Seibold S, Schmitt T (2019) Agricultural intensification drives butterfly decline. Insect Conserv Divers 12:289-295

Hassel MP, May RM (1986) Generalist and specialist natural enemies in insect predator-prey interactions. J Anim Ecol 55:923-940

Holland JM, Reynolds CJM (2004) The impact of soil cultivation on arthropod (Coleoptera and Araneae) emergence on arable land. Pedobiologia 47:181-191

Jacobsen SK, Moraes GJ, Sørensen H, Sigsgaard L (2019) Organic cropping practice decreases pest abundance and positively influences predator-prey interactions. Agric Ecosyst Environ 272:1-9

Jonsson M, Kaartinen R, Straub CS (2017) Relationship between natural enemy diversity and biological control. Curr Opin Insect Sci 20:1-6

Lalonde O, Légère A, Stevenson FC, Roy M, Vanasse A (2011) Carabid beetle communities after 18 years of conservation tillage and crop rotation in a cool humid climate. Can Entomol 144:645-657

Landis DA, Menalled FD, Costamagna AC, Wilkinson TK (2005) Manipulating plant resources to enhance beneficial arthropods in agricultural landscapes. Weed Sci 53:902-908

McGill BJ, Enquist BJ, Weiher E, Westoby M (2006) Rebuilding community ecology from functional traits. Trends Ecol Evol $21: 178-185$

Navntoft S, Kristensen K, Johnsen I, Jensen A-MM, Sigsgaard L, Esbjerg P (2015) Effects of weed harrowing frequency on beneficial arthropods, plants and crop yield. Agric for Entomol 18:59-67

Navntoft S, Sigsgaard L, Nimgaard R, Esbjerg P, Kristensen K, Andresen LC, Johnsen I (2009) Bufferzones for biodiversity of plants and arthropods: is there a compromise on width? Danish Environmental Protection Agency. Pestic Res 127

Nawaz A, Ahmad JN (2015) Insect Pest Management in Conservation Agriculture. In: Farooq M, Siddique KHM (eds.) Conservation Agriculture. Springer International Publishing, Switzerland.

$\mathrm{Ng} \mathrm{K}$, Driscoll DA, MacFAdyen S, Barton PS, McIntyre S, Lindenmayer DB (2017) Contrasting beetle assemblage responses to cultivated farmlands and native woodlands in a dynamic agricultural landscape. Ecosphere 8:e02042

Nolte D, Boutard E, Kotze DJ, Schuldt A, Assmann T (2019) Habitat specialization, distribution range size and body size drive extinction risk in carabid beetles. Biodivers Conserv 28:1267-1283

Nyffeler M, Benz G (1988) Feeding ecology and predatory importance of wolf spiders (Pardosa spp.) (Araneae, Lycosidae) in winter wheat fields. J Appl Entomol 106:1-5

Öberg S, Ekbom B (2006) Recolonization and distribution of spiders and carabids in cereal fields after spring sowing. Ann Appl Biol 149:203-211

Pedersen JL, Wejdling H (2019) Conservation Agriculture, agerhønsene og de andre fugle. Momentum+ 4: 16-20

Peterson G, Allen CR, Holling CS (1998) Ecological resilience, biodiversity and scale. Ecosystems 1:6-18

R Core Team (2020) R: A language and environment for statistical computing. R Foundation for Statistical Computing, Vienna, Austria. URL https://www.R-project.org/

Roberts MJ (1985) The Spiders of Great Britain and Ireland (Compact Edition). Part I and II. Harley Books, Essex, England
Rouabah A, Lasserre-Joulin F, Amiaud B, Plantureux S (2014) Emergent effects of ground beetles size diversity on the strength of prey suppression. Ecol Entomol 39:47-57

Rowen EK, Regan KH, Barbercheck ME, Tooker JF (2020) Is tillage beneficial or detrimental for insect and slug management? a metaanalysis. Agric Ecosyst Environ 294:106849

Rusch A, Birkhofer K, Bommarco R, Smith HG, Ekbom B (2015) Predator body sizes and habitat preferences predict predation rates in an agroecosystem. Basic Appl Ecol 16:250-259

Rusch A, Chaplin-Kramer R, Gardiner MM, Hawro V, Holland J, Landis D, Thies C, Tscharntke T, Weisser WW, Wingqvist C, Woltz M, Bommarco R (2016) Agricultural landscape simplification reduces natural pest control: a quantitative synthesis. Agric Ecosyst Environ 221:198-204

Sapkota TB, Mazzoncini M, Bàrberi P, Antichi D, Silvestri N (2012) Fifteen years of no till increase soil organic matter, microbial biomass and arthropod diversity in cover crop-based arable cropping systems. Agron Sustain Dev 32:853-863

Sigsgaard L, Toft S, Villareal S (2001) Diet-dependent fecundity of the spiders Atypena formosana and Pardosa pseudoannulata, predators in irrigated rice. Agric for Entomol 3:285-295

Sigsgaard L (2000) Early season natural biological control of insect pests in rice by spiders-and some factors in the management of the cropping system that may affect this control. Eur Arachnol 57-64

Snyder WE (2019) Give predators a complement: Conserving natural enemy biodiversity to improve biocontrol. Biol Control 135:73-82

Snyder WE, Snyder GB, Finke DL, Straub CS (2006) Predator biodiversity strengthens herbivore suppression. Ecol Lett 9:789-796

Straub CS, Finke DL, Snyder WE (2008) Are the conservation of natural enemy biodiversity and biological control compatible goals? Biol Control 45:225-237

Symondson WOC, Sunderland KD, Greenstone MH (2002) Can generalist predators be effective biocontrol agents? Annu Rev Entomol 47:561-594

Symondson WOC, Cesarini S, Dodd PW, Harper GL, Bruford MW, Glen DM, Wiltshire CW, Harwood JD (2006) Biodiversity vs. biocontrol: positive and negative effects of alternative prey on control of slugs by carabid beetles. Bull Entomol Res 96:637-645

Tamburini G, Simone SD, Sigura M, Boscutti F, Marini L (2016) Conservation tillage mitigates the negative effect of landscape simplification on biological control. J Appl Ecol 53:233-241

Thomas CFG, Marshall EJP (1999) Arthropod abundance and diversity in differently vegetated margins of arable fields. Agric Ecosyst Environ 72:131-144

Thorbek P, Bilde T (2004) Reduced numbers of generalist arthropod predators after crop management. J Appl Ecol 41:526-538

Tscharntke T, Klein AM, Kruess A, Steffan-Dewenter I, Thies C (2005) Landscape perspectives on agricultural intensification and biodiversity - ecosystem service management. Ecol Lett 8:857-874

Tscharntke T, Karp DS, Chaplin-Kramer R, Batary P, DeClerck F, Gratton C, Hunt L, Ives A, Jonsson M, Larsen A, Martin EA, Martinez-Salinas A, Meehan TD, O'Rourke M, Poveda K, Rosenheim JA, Rusch A, Schellhorn N, Wanger TC, Wratten S, Zhang W (2016) When natural habitats fails to enhance biological pest control - Five hypotheses. Biol Conserv 204:449-458

Publisher's Note Springer Nature remains neutral with regard to jurisdictional claims in published maps and institutional affiliations. 